\title{
Re-significando la Educación Sexual Integral desde el trabajo social
}

Resignifying Comprehensive Sexual Education from Social Work Ivanoff Maria Fernanda ${ }^{1}$ Muñoz Rubia Idania Macarena² Ortiz Martín Carla Daniela ${ }^{3}$

\section{Resumen}

El presente artículo pretende describir prejuicios e imaginarios sociales presentes en la implementación de la Educación Sexual Integral (ESI) a través de la adhesión a la Ley 26150/06 en la provincia de San Juan, a partir del año 2018. Nos propusimos identificar cómo conciben la sexualidad las personas entrevistadas en relación a sus imaginarios sociales sobre la ESI; en segunda instancia visibilizar la existencia de prejuicios que podrían influir en la implementación de dicha ley; y por último identificar el rol del/la Trabajador/ra Social en los diversos escenarios de actuación profesional en relación a dicha temática. La investigación se llevó a cabo con metodología de tipo cualitativa, indagación en fuentes primarias y secundarias, y realización de entrevistas semi-estructuradas, efectuadas a quienes dictaron y/o asistieron a capacitaciones sobre ESI.

Palabras clave: educación sexual integral, imaginarios sociales, prejuicios, trabajo social

\section{Abstract}

This article aims to describe prejudices and social imaginary in the implementation of Comprehensive Sexual Education (ESI) through adherence to the Law 26150/06 in the province of San Juan, starting in 2018. We set out to identify how the interviewees conceive sexuality in relation to their social imaginary about CSE; in the second instance, to make visible the existence of prejudices that could influence the implementation of that Law; and finally, to identify the role of the social worker in the various professional performance scenarios related to that issue. The research

\footnotetext{
Recibido: 30 de septiembre de $2020 \sim$ Aceptado: 21 de diciembre de $2020 \sim$ Publicado: 1 de enero de 2021

${ }^{1}$ Licenciada en Trabajo Social. Universidad Nacional de San Juan (UNSJ), San Juan, Argentina. Correo electrónico mariafernandaivanoff@yahoo.com

${ }^{2}$ Licenciada en Trabajo Social. Universidad Nacional de San Juan (UNSJ), San Juan, Argentina. Correo electrónicoimr18@hotmail.com

${ }^{3}$ Licenciada en Trabajo Social. Investigadora Independiente, San Juan, Argentina. Correo electrónico danii911056@gmail.com
} 
was carried out with a qualitative methodology, inquiring into primary and secondary sources, and conducting semi-structured interviews, conducted with those who gave and / or attended training on ESI.

Keywords: comprehensive sex education, social imaginaries, prejudices, social work

\section{Introducción}

El artículo actual tiene como intención, desarrollar y analizar información obtenida durante una investigación realizada en el año $2019^{4}$, la cual fue puesta en marcha por medio de una metodología de tipo cualitativa (Hernández Sampieri, 2014, pp. 406-487), realizando en principio un buceo bibliográfico y documental, para luego efectuar entrevistas orientadas a una unidad de muestra conformada por personas que dictaron o asistieron al dictado de diferentes capacitaciones, relacionadas con la implementación de la Educación Sexual Integral en la provincia de San Juan, Argentina.

La misma pretendió elucidar algunos de los motivos que pueden estar obstaculizando la implementación de la ESI en la provincia de San Juan, a partir de la adhesión a la Ley 26150/06 en el año 2018. Por lo tanto, se realizó una vinculación entre la investigación social y la intervención profesional, a partir del rol que se ejerce desde el trabajo social y en relación a la temática mencionada.

Durante el desarrollo del presente texto, se pretende efectuar una vinculación entre una dimensión teórica y una dimensión empírica, para plasmar las discrepancias existentes entre lo planteado en los conceptos autorales y de cómo es percibida la sexualidad en la realidad social a partir de la inserción en ella y desde allí, tomar conocimiento de los relatos, mandatos, normas culturales, etc., que forman parte de los imaginarios sociales que transversalizan a los/las entrevistados/as.

Además de ello, poder mostrar la existencia de prejuicios existentes en la sociedad sanjuanina, los cuales podrían estar influyendo en la implementación de la Ley No 26150/06, teniendo en cuenta, además, que la adhesión provincial a la misma se produjo doce años después de que la ley fuera promulgada a nivel nacional.

Por último, nuestra finalidad es realizar aportes diversos a partir de la identificación del o los roles del/la trabajador/a social en los diferentes escenarios

\footnotetext{
${ }^{4}$ Trabajo final de investigación, titulada "ESI, una mirada desde el trabajo social”, realizado en la Universidad Nacional de San Juan (UNSJ), dirigida por el Dr. Antonio De Tommaso.
} 
de actuación profesional, con respecto a la Educación Sexual Integral, y partiendo desde la intervención del trabajo social enlazada a la investigación social.

Es relevante referir, que el presente escrito se basa en lineamientos desde la perspectiva de género ${ }^{5}$ y el enfoque de derechos ${ }^{6}$.

En virtud de lo anteriormente descrito y como cierre del presente artículo, se realizan las conclusiones pertinentes acorde al desarrollo del mismo, aportando también nuestras reflexiones finales.

\section{La sexualidad a partir de los imaginarios sociales de la sociedad sanjuanina:}

Reflexionando en torno a la influencia de los imaginarios sociales en la aplicación de la Ley de Educación Sexual Integral para su implementación en la provincia de San Juan, citamos a Bonaccorsi y Reybet (2008) quienes enuncian:

Los mandatos culturales a las mujeres establecen que su rol natural y social es la reproducción de la especie. A partir de estos preconceptos impuestos, el feminismo contemporáneo denuncia la maternidad obligatoria y la heteronormatividad al proponer repensar los mandatos sociales, a la vez que separar sexualidad de reproducción y objetivar la maternidad como un proyecto de vida, por lo tanto planificada como todo proyecto (p.54).

También como refiere la UNESCO (2010) a través de sus estudios e investigaciones acerca de la Educación Integral de la Sexualidad: "la sexualidad es un aspecto básico de la vida humana, con dimensiones físicas, psicológicas, espirituales, sociales, económicas, políticas y culturales” (p.37).

Sin embargo, ésta es una concepción reciente que todavía tiene sus resistencias; el análisis de Korinfeld (2005) describe:

La sexualidad en la escuela pareciera que ha sido una suerte de secreto abierto, que ha circulado en distintos tipos de intercambios. Si bien la escuela ha guardado cierto "silencio" respecto de la sexualidad, generando una marcada diferencia con el tratamiento del tema en los medios de comunicación, por ejemplo; este silencio contrasta con la puesta en circulación de un conjunto

\footnotetext{
${ }^{5}$ La perspectiva de género es un conjunto de creencias, características de personalidad, actitudes, valores, conductas y acciones cotidianas que diferencian a hombres y mujeres, masculinidades y feminidades en la sociedad (Burin, 1998).

${ }^{6}$ El enfoque de derechos considera que los sectores excluidos de la sociedad son titulares de derechos que obligan al Estado a garantizar un conjunto de necesidades insatisfechas (Niremberg, 2013).
} 
de expectativas, ideales, comportamientos, prohibiciones y prescripciones para los niños y niñas, hombres y mujeres (p.48).

Además, teniendo en cuenta a Louro (citado en Villa, 2007, p.219), considera que sería importante señalar que:

La sexualidad no es apenas una cuestión personal, sino que es una cuestión social y política; el segundo es el hecho de que la sexualidad es aprendida, o mejor es construida, a lo largo de toda la vida, de muchos modos, por todos los sujetos

Por lo tanto, consideramos que debe tenerse en cuenta que la sexualidad es un elemento que forma parte de las subjetividades de las personas, y que excede el encuentro de tipo sexual; sin dejar de considerar que se trata de algo biológicamente adquirido, siendo parte de una construcción social e individual, es decir, que esta adquisición nos transversaliza desde que nacemos y a lo largo de nuestra trayectoria de vida, re-construyendo y transformando la idea que concebimos de sexualidad. El ser hombre o ser mujer es diferente desde lo cultural, desde las condiciones sociales de existencia, desde la pertenencia étnica, desde la orientación y preferencia sexual, entre otros aspectos.

Esta construcción es altamente dinámica y cambiante en el transcurso del tiempo, los sentidos que le atribuimos van transformándose y re-significándose a lo largo de nuestras vidas. Las múltiples dimensiones del concepto de sexualidad se encuentran en la definición de la Organización Mundial de la Salud (2015):

La sexualidad es un aspecto central del ser humano presente a lo largo de su vida. Abarca el sexo, las identidades y los papeles de género, la orientación sexual, el erotismo, el placer, la intimidad y la reproducción. La sexualidad se evidencia y se expresa a través de pensamientos, fantasías, deseos, creencias, actitudes, valores, conductas, prácticas, papeles y relaciones interpersonales. La sexualidad puede incluir todas estas dimensiones, no obstante, no todas ellas se evidencian o se expresan siempre. La sexualidad está influida por la interacción de factores biológicos, psicológicos, sociales, económicos, políticos, culturales, éticos, legales, históricos, religiosos y espirituales (p.3)

Considerando que el concepto de sexualidad es multifacético, abarcando una compleja y dinámica cantidad de aristas, la misma será definida y construida de diversas maneras, no existiendo una única forma de considerarla desde la sociedad; a partir de ello, aludimos al siguiente comentario de un/a entrevistado/a: "hay todo un escenario social, (...) familiar, (...) cultural donde estamos insertos. Nos 
movemos, comemos, gritamos, cantamos como varón, nos gusta hacer cosas de varones, jugamos como varones y al igual las nenas".

Pueden observarse claramente en lo expuesto por el/la entrevistado/a, la presencia de varias cuestiones a interpretar: en principio, la pre-existencia de mandatos socio-culturales y familiares, que condicionarían los modos de accionar y relacionarse de las personas; posteriormente las "cosas que llevan a cabo los varones y las que conciernen a mujeres" esto tiene que ver con roles sociales/familiares estereotipados y asignados precedentemente a cada uno de ellos, paralelamente surgen caracterizaciones hetero-normativas y hetero-biológicas.

Otro rasgo observable e interpretativo, es lo relacionado a la producción y reproducción de normas y mandatos íntimamente vinculados a una variedad de representaciones y construcciones de sexualidad, género, entre otros, que se van dando en la sociedad.

Otro/a de los/as entrevistados/as opina:

Las chicas adolescentes (...) que son madres, ahí en maternidad, no conocen nada, o directamente el médico les quiere implementar un método anticonceptivo, cuando en realidad no tiene porque, o hay chicas que a veces tienen 22 años, 23 y se quieren ligar y les dice el ginecólogo: “No, ¿para qué te vas a ligar, si sos joven?” Vos fíjate el nivel de ignorancia del profesional con respecto a cuestiones legales.

En el relato precedente, se evidencia el hecho de una mirada de la sociedad con el hecho de "ser mujer" en profunda relación al "rol de madre" "como medio para" la procreación y reproducción biológica, social y familiar.

Otro rasgo interpretativo para traer a colación, es la coexistencia de varias perspectivas en relación a la educación sexual, entre ellas el modelo médicobiológico, el cual se visibiliza en las palabras del segundo relato, al hacer mención de las actuaciones de ciertos profesionales en el área de salud y su desinformación o falta de adhesión a las leyes vigentes.

Con respecto a la sexualidad cómo construcción un/a entrevistado/a nos refiere:

Para mí la sexualidad es eso, una construcción de cada uno como seres únicos que somos, nos debemos respetar, (...) valorar como personas, que eso también hay ciertos mandatos socio-culturales que interfieren con nosotros, entonces no nos podemos desenvolver como queremos. 
Se hace referencia a la sexualidad como constructo, enlazándola al respeto y a los valores. Hay que señalar, además, la mención de los mandatos socio-culturales como obstaculizadores de un desenvolvimiento deseado de la misma.

De acuerdo a la sexualidad en el ámbito escolar, en una primera narración se nos expresa:

Cuando dan talleres, (...), lo dan desde un modelo desde lo biológico y desde la morbosidad, (...), quieren educar desde lo violento, lo morboso, de cómo asustarte, hoy en día eso ya no existe, hay que modificar las formas, las conductas de quienes dan los talleres y siempre desde el beneficio y no desde el perjuicio.

Otro/a entrevistado/a comenta: "los niños van con muchas preguntas a la escuela, yo considero que trabajándolo bien es muy positivo que se dé educación sexual en la escuela".

Una vez más se hace alusión a modelos/miradas coexistentes en relación a la producción y transmisión de contenidos alusivos a la educación sexual, en esta ocasión el modelo médico/biológico y el modelo de riesgo. Al señalar el hecho de modificar conductas y formas de transmisión de estos conocimientos, citando al/la primero/a de los/las entrevistados/as quien considera que debiera ser "desde el beneficio y no desde el perjuicio" y el/la entrevistado/a siguiente comenta “trabajándolo bien es muy positivo que se dé educación sexual en la escuela”, podría esbozarse cómo un accionar afín a las visibilizaciones (en relación a las transformaciones actuales de nuestra sociedad), a posturarnos en nuestro accionar desde el enfoque de derechos.

En concordancia con las narraciones anteriores, agregamos el siguiente relato:

Tan solo confiar que con esa educación informal hogareña alcanza, no está a tiempo, (...), donde el niño tiene acceso al celular, (...), a ver, a investigar, en una velocidad cinco veces más, de lo que el padre leía y estudiaba a esa misma edad, (...), entonces si el adulto no está verdaderamente preparado y formado, la información que va a poder dar es mínima, (...), y no porque al niño se le niegue información, lo voy a tener (...), mejor resguardado.

Del mismo modo nos enuncia otro/a entrevistado/a:

Falta mucho todavía, estamos recién en los primeros pasos, y creo que falta mucha concientización y educación al educador, o sea los docentes no están formados ni preparados para abordar estos temas, no saben cómo hacerlo y tienen también muchos prejuicios, por lo menos eso es lo que veo acá en San Juan. 
De estos relatos surge una nueva particularidad en relación a la educación sexual y en cuanto a la accesibilidad, celeridad de obtención de información de forma ilimitada por parte de niños/as, adolescentes y jóvenes; todo ello en forma paralela a la débil formación y preparación por parte de los/as adultos/as.

A ello se suma lo referido en la segunda narrativa, en relación a considerar la ausencia de concientización/educación por parte de los/las docentes, para impartir las enseñanzas en relación a la temática planteada; además de la falta de estrategias y herramientas en adición a la existencia de prejuicios, en los/las adultos/as que tienen a cargo esa tarea. En un primer comentario se nos expresa: "entonces van a haber mamás que les va a gustar y hay otras que no, y están en todo su derecho, o sea, eso la ley lo contempla"; por otra parte nos refieren:

No vamos a preguntarle nada fuera de lugar, no le vamos a llenar la cabeza, no le vamos a pasar una película porno, que eso es lo que asusta a los padres, por eso tienen tanta reacción. "Se le está dando algo y nadie me ha consultado", si jamás para darle geometría al niño le vamos a consultar.

Aquí son más que evidenciables los "silenciamientos y prohibiciones" de los cuales hablamos. En principio, en el primer relato, se realiza una interpretación de la Ley 26.150/06 que no es tal, la misma no contempla el hecho de que las instituciones educativas deban por su parte, solicitar autorización a los adultos responsables para impartir ESI en sus aulas, del mismo modo en que no deben hacerlo para impartir conocimientos de otro tipo (tal como se enuncia en el comentario subsiguiente). En relación a ello, un/a entrevistado/a nos refiere:

Dentro de la ESI está el cuidado de valores, (...) de la causa-efecto. El adolescente se gesta o crece en un ambiente donde está apadrinado por padres o por situaciones sociales, en torno a políticas sanitarias, (...), nosotros te bancamos ¿dónde lo bancamos? ¿no querés estudiar?, te bancamos, ¿querés estudiar?, te bancamos y te pagamos, ¿querés tener relaciones?, te pagamos el forrito, ¿te embarazaste?, no te preocupes, ¿no lo querés ahora?, con la ley o el intento de protocolo nuevo, te lo sacamos. ¿Querés?, te estoy siempre esponsorizando por atrás. Y ¿en qué momento la gente asume la responsabilidad de la causa-efecto?

Precedentemente, se refleja una serie de descripciones y representaciones de tipo simbólicas, en las cuales hay una presencia de "estructuraciones e irreductibilidades" en las ideas manifestadas por el/la entrevistado/a. Dichas ideas consideradas por el/la mismo/a muestran categorizaciones en los pensamientos, y cómo éstas desde una mirada amplia, demuestran ciertas concepciones generalizadas 
de la sociedad que conforman otras más específicas, como por ejemplo las formas o modos de educación sexual que puedan poner en marcha las personas en su accionar cotidiano y desde su estatus social.

De acuerdo a lo que refiere el concepto de sexualidad, un/a entrevistado/a enuncia:

La sexualidad, para mí es única de cada persona, que cada uno la construye, pero esa construcción a veces se ve distorsionada por la familia, justamente por sus creencias y sus valores, entonces muchas veces es ahí, cuando a veces, entramos con pequeños percances a la hora de llevar adelante lo que uno quiere hacer como profesional, como implementar la ESI (Educación Sexual Integral).

En el testimonio anterior, se hace alusión a la sexualidad como una construcción y al mismo tiempo enuncia al ámbito familiar como parte importante de la misma, lo cual se hace presente en las situaciones que se presentan a la hora de desempeñarse en sus funciones, como un posible obstaculizador, por lo que exponemos el siguiente relato del entrevistado/a:

A la familia la incorporas como un factor súper beneficioso, en la formación, y ahí te puedo decir que la palabra integral se completa. Educación como todo niño, en lo sexual perfecto, pero en lo integral es eso, en todos los aspectos, y ahí entra la familia, fundamental, vital, pero hay un desconocimiento en este tema puntual, en lo que educación sexual, se merece en todos los estratos etarios, (...), porque haciendo un poco de recuerdo, (...), nuestros padres de 60, 70 años tienen un vacío en lo que es la educación sexual, lo que hace que sean bastantes huérfanos en el conocimiento a la hora de tener que educar a los hijos, a nosotros mismos ¿no?

En este caso, el/la entrevistado/a describe a la familia como beneficiosa, como fundamental y sustentando en ella a la "integralidad" enunciada en la ley 26.150/06. Esta integralidad que menciona la ley está relacionada con las emociones, con los sentimientos, con los valores, con el respeto de la intimidad propia y ajena, con los derechos de las personas, con la igualdad de trato para hombres y mujeres, con el respeto sin distinción de la orientación sexual, entre otras cuestiones.

Aun así, el/la entrevistado/a también menciona el hecho del desconocimiento en las familias, en cuanto a educación sexual, alude a un vacío, una orfandad en lo que a conocimientos de la temática se refiere, lo que a su vez interviene en su transmisión generaciones posteriores, aquí entran en juego los caracteres 
inherentes a la sexualidad cómo construcción individual y social (y por ende, familiar).

Es decir, al referir a la integralidad, consideramos la perspectiva multifacética de la sexualidad, refiriéndonos a las miradas desde las redes primarias como las familias, las redes secundarias como las instituciones educativas, y redes comunitarias en general, en las cuales se manifiestan diversas dimensiones culturales y/o valorativas, que determinan una forma de mirar y definir la sexualidad.

Teniendo en cuenta que la sexualidad es un aspecto central del ser humano, en otro fragmento de la entrevista se desprende lo siguiente:

Les hago la diferencia de lo que es la sexualidad y lo que es la genitalidad, porque nosotros somos personas sexuadas desde el nacimiento ¿no?, pero en esa sexualidad no solamente acompañan los órganos, acompaña toda la persona, su espíritu, su alma, su mentalidad, entonces, hablar de sexualidad es hablar de algo integral, somos todo, nuestra sexualidad nos acompaña a todos lados, (...), no solamente lo racional y lo corporal, tenemos la parte espiritual también, somos un cuerpo y un alma, entonces la sexualidad es también digamos, (...), siempre hay que diferenciarlo de la parte de la genitalidad.

Otro/a entrevistado/a, comenta:

No sólo está relacionado con la genitalidad, sino que, al contrario, es un concepto mucho más integral, que abarca la forma en que los seres humanos nos relacionamos con otros, la forma que entendemos el mundo, es como lo que nos identifica, es la libido, es la energía vital.

Desde ambas posturas se expresan en forma clara dimensiones que están consideradas dentro del concepto de sexualidad de la OMS, y del mismo modo, cómo en ocasiones se manifiestan algunas u otras, y las modificaciones que se van dando al transcurrir el tiempo.

En relación a todo lo relatado precedentemente, podemos percibir que existe una repercusión de los imaginarios sociales respecto a la implementación de la ESI en la provincia de San Juan. Dichos imaginarios se caracterizan por ser conservadores y negados a transformaciones sociales en vinculación con una realidad permanentemente cambiante.

\section{Investigación en relación a la existencia de prejuicios en la sociedad sanjuanina}


En relación a esta cuestión, nos propusimos visibilizar la posible existencia de prejuicios en la sociedad sanjuanina, que pudieron influir en la implementación de la ESI (ley N²6.150/06) en la provincia.

Con respecto a los prejuicios, Del Olmo (2005) refiere "que aceptamos una idea de otras personas cuando confiamos en ellas o en su opinión particular, no necesariamente en general (...) bien por su autoridad o la credibilidad que nos merece (...) sin tener que experimentar previamente con ellas” (p.15). Por ejemplo, en procesos de enseñanza/aprendizaje la autora subraya la importancia del trabajo de Allport (Del Olmo, 2005, p.14), demostrando que los prejuicios no estaban determinados por el tipo de personalidad de cada cual sino que los aprendemos desde pequeños/as. La comunicación humana contiene muchos ejemplos, Del Olmo considera que adquirir prejuicios no es algo negativo solamente, sino que nos permite acumular experiencia de los demás y hacerla nuestra, multiplicando la información sobre nuestro entorno, cosas y personas de nuestro alrededor, sobre las relaciones que entablamos o podemos entablar. De este modo, podemos elaborar categorías y predecir el comportamiento de los elementos que las integran; y, en consecuencia, orientarnos.

Por otra parte, según Casas Martínez (2008):

(...), el prejuicio no es solamente una declaración de opinión o de creencia, sino una actitud que incluye sentimientos como desprecio, disgusto o repudio, y del mismo modo, es raro que los estereotipos queden atrás. El concepto 'estereotipo' hace referencia a reproducciones mentales de la realidad, generalizaciones de miembros $\mathrm{u}$ objetos de algún grupo, los prejuicios como las generalizaciones pueden poseer contenido positivo o negativo (p.151).

Por lo tanto el prejuicio, el estereotipo y la discriminación con frecuencia se presentan juntos. Tal como recuperan Casas \& De la Luz, Theodor Adorno concluyó que la clave del prejuicio se atribuía a una "personalidad autoritaria" de personas con pensamiento rígido que obedecen a la autoridad, con una visión del mundo en forma de jerarquías, un apego estricto a las reglas sociales, con miedo a perder el control (Adorno en casas y De la Luz, 2008, p.151). Sus coautores ${ }^{7}$ resaltan el pensamiento categórico rígido como ingrediente central en el prejuicio, con dimensiones emocionales, sociales, económicas e históricas, como parte del funcionamiento normal del ser humano, como proceso que no puede ser evadido. Una consecuencia del pensamiento categórico es su tendencia a distorsionar

\footnotetext{
${ }^{7}$ Frenkel-Brunswik, Else; Levinson, Daniel J.; Nevitt Sanford, R.
} 
percepciones que minimizan las diferencias (asimilación) o exageran las diferencias entre categorías (contraste), es decir, que en la práctica las diferencias intragrupales tienden a ser minimizadas y las diferencias intergrupales tienden a ser exageradas; si las mismas son consistentes con estereotipos bien conocidos, la distorsión en la percepción puede ser altamente resistente al cambio, derivando en una forma más de creencia, referida a grupos propios o externos. Cuando se trata de actitudes, valores, rasgos de la personalidad la gente tiende a estereotipar a personas de grupos externos, privándolas de su individualidad, esta percepción de homogeneidad se mantiene sin importar cuál sea el grupo externo. Las personas con prejuicios tienden a reconocer solo en su grupo interno cualidades positivas. Estos mecanismos son parte del funcionamiento humano normal, pero deben ser comprendidos, orientados y manejados de una forma humanizada en la sociedad.

La educación es un proceso de comunicación humana, con características particulares, por ende, los prejuicios se presentan constantemente. Pero en un contexto diverso (como es la escuela) no son solo menos efectivos, sino perjudiciales y paradójicamente suelen emplearse con mayor frecuencia, por ejemplo con respecto a la sexualidad. Morgade en Ramos (2009), refiere: que "es un proceso histórico, social y psíquico incesante. Como toda producción humana tenemos relaciones de conformidad y de resistencia, de cooperación y de conflicto, donde se producen significados que llevan a legitimar objetivos y valores que proponen acciones comunes" (p.158). Además la autora (Morgade, 2009) enuncia que: "maestras y maestros, profesoras y profesores también son personas sexuadas, con experiencias y creencias que son interpeladas de manera constante y deben ser respetadas e incluidas cuidadosamente en una formación específica” (p.47).

Para la autora Pauluzzi, citada en Villar y otras (2016) "no abordar ejes de educación sexual, pone en complicidad directa a la docencia con los delitos de abuso y maltrato, por solo el hecho de silenciar la temática” (p.13). Entendemos que hablar de sexualidad con los estudiantes es complejo, rodeado de temores y tabúes, pero debe ser considerado un proceso donde cada actor institucional debe construir un espacio propio, adecuarse a ello.

A partir de lo descrito, recuperamos el siguiente relato: "pienso que es una sociedad muy conservadora la nuestra (...), por miedo, por temor (...), en general las ciudades chicas tienen estas características, nosotros no somos una excepción a la regla”

El/la entrevistado/a expresa una visión conservadora de la provincia, que puede estar ligada a transmisiones de ideas incorporadas durante el transcurso de nuestras vidas. Luego, se evidencia que el/la entrevistado/a infiere lo siguiente: "esta 
sociedad, según mi punto de vista (...), no tiene los conocimientos necesarios para llevar una adecuada sexualidad".

Desde el trabajo social, la intervención y la investigación científica son centrales para el reconocimiento del "Otro", al develar la trama política de las formas de nominación y control social, con la revisión crítica de las categorías en su clave histórica y social. Por otra parte, es necesario otorgar espacio a la palabra del "Otro", como acción de hablar y como acto que otorga sentido a sus prácticas y su vida cotidiana, reconociendo los lugares de poder y empoderamiento desde los que se constituye el diálogo, la enunciación y la capacidad de escucha.

Comenta un/a entrevistado/a: "gente que es católica y que dice no la ley de ESI, porque a mis hijos no les vas a enseñar", otro de los relatos nos dice:

Quizás (...) personas que están en contra, (...) no creo que lo hayan analizado en profundidad (...), tienen mucho que ver la Iglesia y esta tradición nuestra de que todo quede dentro del ámbito familiar, de que no se hable, de que no salga a la luz.

Además de tener en cuenta que los prejuicios son aprehendidos por medio de transferencia de ideas provenientes desde el entorno (en este caso la familia y la iglesia) consideramos que también son adquiridos por medio de las experiencias propias y singulares. Según lo expuesto en el segundo testimonio, en relación a las personas católicas respecto de la ESI, paralelamente el/la entrevistado/a anterior refiere que se debe a que no conocen la ley de ESI en profundidad. Otro/a entrevistado/a menciona: "Yo soy profesor/a, no soy un doctor/a para saberlo todo".

Lo que evidencia el último testimonio mencionado, es que un gran porcentaje de la sociedad, considera que solo un/a médico/a está habilitado/a para impartir conocimientos sobre ESI. Casas Martínez (2008) expone "las categorías como recursos mentales para acortar razonamientos" (p.151), explicitándose en los siguientes testimonios:

Eso hace al contexto de la sexualidad, y por eso (...), nos empiezan a atraer los opuestos (...), las carencias, lo que uno no tiene. Y es ahí donde, (...), empiezan a conocer la atracción al sexo opuesto, ahí puede haber un montón de grises y cuando, (...), no sucede, (...), es otro tema.

En un segundo relato, el mismo entrevistado nos comenta: “¿te descubriste como mujer? (...), ¿tenés capacidad de disfrutar?, gozá pero no te embaraces, eso dista muchísimo de un objetivo de la educación sexual integral, porque la palabra integral tiene que ver con todo". 
Adorno (citado en Casas Martínez, 2008, p.151), concluye que la personalidad autoritaria mira al mundo desde las jerarquías apegándose estrictamente a reglas sociales; en los siguientes testimonios se observan los siguientes prejuicios: "si sos pañuelo verde, si sos pañuelo celeste, eso es como que fue un punto en contra, o sea, y no se debatía lo realmente positivo que podía ser para ambas opciones".

En esta expresión se menciona la pertenencia a un grupo u otro, ponderando formas de pensamiento, ideologías y perspectivas, y generando distorsiones en los aportes que se brindan desde la ESI, evidenciadas también en el siguiente relato:

Si a un niño sala de $4,(.$.$) , le ponemos una mujer desnuda y (...) le$ decimos que nombre a los genitales, que el de primer grado o segundo me lo vaya aprendiendo está buenísimo. Si el del primer grado le mostrás una relación sexual explícita cuando el niño todavía no se lo ha preguntado, lo estoy ahí sexuando (...), genitalizando. Y no porque decís, si vos lo sentís, podes, si tenés genitales, es para que te los estimules, si tenés ovarios, es para que lo uses cuando quieras, si vos tenés útero, llénalo cuando vos quieras, y cuando no te venga bien, sácalo.

En ambas narraciones se observa un pensamiento categórico, una exageración, se maximizan las diferencias de ideas contrastadas con otras, reconociendo cualidades positivas solo en el grupo interno; se percibe la ley enlazada a preceptos personales.

Con respecto a ello, nos comentan:

Hay muchos temas que son vidriosos a la hora de irlos a tocar en una clase (...), años atrás (...), con más razón, (...), y si decimos, bueno está institución es la que va a capacitar, estamos recortando también el conocimiento, y más si esas instituciones (...), dependen de (...) una Universidad Católica. Entonces (...), me parece que no vamos a salir formados

En otro relato, nos relatan: "San Juan tiene muchos colegios que dependen del catolicismo (...), hay que darle vuelta de rosca a eso, hay que saber implementarla para que pueda tener una trascendencia mejor".

En el primer testimonio se evidencia la nominación de determinados temas de la ESI, como "vidriosos"; y se enfatiza el intento de mantener la identidad grupal, recortando información a la hora de transmitir el conocimiento. A partir de ello el último testimonio enuncia el hecho de "darle una vuelta de rosca"; desde nuestra postura, una solución sería promover la comprensión, el manejo y la orientación de los mecanismos que estipulan el funcionamiento de los prejuicios. Acorde a lo planteado por Del Olmo (2005), sobre la "educación como proceso específico de 
comunicación humana" (p.20), un entrevistado/a nos dice: "en los colegios confesionales por ahí muchas instituciones te ofrecen ir a dar charlas (...), pero a las directoras les gusta primero hablar qué temas tocarían, desde qué punto de vista”.

En la opinión precedente, se destaca la presencia de abundantes prejuicios que pueden resultar perjudiciales a la hora de brindar los contenidos correspondientes a la ESI, ya que previamente deben ser "evaluados y legitimados" por la autoridad máxima, considerando que tienen la potestad para decidir qué impartir (o no) de la ley 26150/06. De igual forma, se nos relató: "como que ahora están más a flor de piel lo de las mamás, lo de las familias distintas (...), la homosexualidad y toda esta parte".

Teniendo en cuenta que la diversidad ha sido estigmatizada históricamente y aún continúa generando debates, es necesario esclarecerla, para posteriormente enfatizar que es una de las características de comunicación humana, incorporarla previamente, para no generar, ni fortalecer prejuicios. Morgade (citada en Ramos, 2009, p.158), "la sexualidad es una producción humana, con relaciones de conformidad/resistencia”, por consiguiente consideramos el siguiente relato:

En las redes sociales, hace unos meses atrás, una maestra (...), mandó un videíto en Córdoba que bajó de YouTube (...), erró en contenido, pero generó un revuelo que la querían quemar viva, yo la hubiese quemado viva (...). Pero a lo mejor tenía la mejor de las intenciones, pero si detrás de estos hay gente que arma contenido (...), no que traiga a un cualquiera, o un izquierdista o una derecha extrema.

Son significativas las palabras del/la entrevistado/a, ya que relacionan el concepto de sexualidad como proceso histórico, social y psíquico. El/la entrevistado/a pretende expresarse en relación al contenido y a quién lo imparte, pero resulta relevante la comparación que realiza sobre la docente, con la época de la inquisición, excluyendo el concepto de humanización; acota la idea de un perfil específico, con ciertas características, por parte de las personas que actualmente brindan conocimientos de ESI; por ello nos preguntamos: ¿en base a qué criterios? ¿Desde el estereotipo, la estigmatización, la discriminación? También comenta:

Está el conservador que dice, prefiero que, (...), pase por zonzo y no por avivado, y el otro extremo, (...), hay que darle con todo, (...), mientras se sepa poner y sacar un preservativo hemos cumplido con el objetivo de la ESI y que dista muchísimo de esto.

El/la entrevistado/a equipara brindar ESI con el hecho de colocar un preservativo, pudiendo ser su concepción en relación a los contenidos que se imparten desde la misma; genera un antagonismo cuando menciona que ello dista 
del objetivo de la ley. Además, mencionamos el siguiente comentario: "se les va a pedir permiso a los padres, viste que si dejan que sus hijos participen y van a haber padres que te van a decir que no”.

La ley se interpreta confusamente, se ve influenciada por la desinformación, la transversalización de los mandatos, valores, creencias (relación de resistencia) y el temor de que las familias tomen acciones legales (relación de conflicto). A partir de lo enunciado por Morgade (2009), acorde al hecho de que "maestras/os y profesoras/as son sujetos/as sexuados/as" (p.47), exponemos el siguiente relato:

Me ha pasado cuando damos los talleres, que no puede ir cualquier persona lamentablemente a dar un taller de educación sexual (...), porque a veces las creencias de uno interfieren en el taller y no puede ser neutro, por más que seamos (...), profesionales (...), eso interfiere.

Otro/a entrevistado/a nos enuncia: "a veces los responsables en llevar adelante esa propuesta (...), no tenemos las herramientas (...), para poder ejecutarla, por cuestiones de cada uno (...), personales, de valores” y por último, otro comenta: "Cuando te aparece el tema de la masturbación (...), es un tema delicado (...), que hasta lo tenemos que trabajar en conjunto".

Aquí se observan distintas características en los/las docentes a la hora de brindar ESI a los/las estudiantes, elucidando que podrían estar interfiriendo ideologías, dogmas y la ausencia de capacitaciones necesarias que les brinden herramientas. Teniendo en cuenta los silenciamientos en las escuelas que influyen en la implementación de la ESI, citamos los siguientes fragmentos:

¿Lo van a avivar al niño? ¿Le van a mostrar una relación sexual explícita?, Ojo que nos ha pasado y es lo que nos pone a todos alerta por dar contenidos fuera de lugar (...), un verdadero sentido de erotización del niño (...), la línea es muy finita, (...), no va con la promoción a la sexualización del niño (...), muchos colegios pueden haber usado ese escudo (...), ¿le vas a sacar (...), matemática de la semana? (...), ¿al idioma? (...), ¿a literatura? (...), ¿a sociales?, y no, no tengo espacio físico para meterlo, entonces inventaron la palabra transversalidad.

Para finalizar agrega: "entonces (...), es el objetivo último de la ESI (...), generar gente sana (...), ciudadanos de bien, y no gente enferma, violadores, abusivos, tipos que no desarrollaron bien su sexualidad en la adolescencia, la juventud".

Estas manifestaciones evidencian y entremezclan aspectos vinculados a temores, tabúes y negaciones que pueden promover consecuentemente, posibles 
situaciones de abuso y maltrato; consideramos que para evitarlos es necesaria la construcción de espacios disponibles y accesibles para abordar la temática. Desde la intervención e investigación, surgen claves centrales para reconocer al otro, por ello destacamos el siguientes fragmento: "entonces (...), esta puja (...) si no es una decisión política, no se va aplicar”.

En relación a ello, se hace presente esta trama política ligada a las relaciones de poder y al control social que se ejerce sobre la población (por ejemplo, aplicando la ley de ESI solamente en los 5tos años en algunas escuelas), por ello, según algunos/as entrevistados/as es ineludible: "hacer valer los derechos sexuales y reproductivos que no todos, ni todas los conocen", añadiendo: "los debates tienen que apuntar a una mejora, pensando en los niños (...), no pensando en los intereses de los más grandes"

Lo enunciado, hace presente la necesidad de un reconocimiento del otro y de la capacidad de escucha que se debería poseer con los/las destinatarios/as, para generar un mayor empoderamiento en ellos/as. Enlazado a ello, en lo expuesto, se evidencia que es fundamental generar espacios que habiliten la palabra del otro, promoviendo un rol activo de las personas. A través de lo anteriormente descrito, se deduce que en cierta medida la presencia de prejuicios de diversa índole en la sociedad sanjuanina, impiden la implementación de la Ley №26.150/06, presentándose de forma explícita o implícita.

\section{Aportes desde la intervención del Trabajo Social en la ESI}

Haciendo referencia al desempeño del/la Trabajador/a social en los diferentes escenarios de actuación profesional, y teniendo en cuenta el Artículo N³ de la Ley $\mathrm{N}^{\circ}$ 27.072/14, según Montaña (2013) es primordial hablar de una "ley que remite a una norma, en esta oportunidad, a una que reconoce derechos (...) desde el marco de los derechos humanos, propiciando derribar algunos paradigmas conservadores acerca de la sexualidad y el género" (p.2).

Teniendo en cuenta los diferentes escenarios de actuación profesional del/la Trabajador/a Social y reconociendo que la ESI es una ley que reconoce derechos; hacemos alusión a lo siguiente, obtenido desde fuentes primarias:

Es un derecho reconocido en la ley de educación nacional, en los pactos internacionales (...), la ESI está contemplada en las leyes, internacionales, nacional y provincial (...), tiene que ser transversal en todos los niveles, y con perspectiva de género y derechos humanos. 
Desde la opinión del/la entrevistado/a puede deducirse que gradualmente y desde distintos ámbitos, se hace un esfuerzo por parte de la población sanjuanina, por interiorizarse acerca de la Ley 26.150/06 y el proceso de implementación de la misma a nivel provincial. Consideramos que desde la difusión apropiada de la misma y una interpretación adecuada, se irán clarificando conceptos y lineamientos que allanarán el camino para llevar a cabo avances y acciones posteriores en relación a la misma.

En el escrito de Érica Montaña (2013) se plantea que la:

Concepción que el Estado le atribuye a la ESI, reconoce en ella, una condición vinculante del mundo de las relaciones subjetivas, como así también llama, a comprender un entramado de prácticas, de búsquedas interminables, que desarrollan las personas, desde la condición de personas sexuadas e histórico-culturales, generando identidades sexuales; he allí su complejidad (p.2).

El autor Di Liscia (citado en Montaña, 2013, p.3) refiere que, para la sanción de una ley: "se requiere de procesos previos dirigidos a aquilatar apoyos, argumentos, antecedentes; la búsqueda de términos que les den existencia y estrategias de abordaje".

A partir de lo desarrollado anteriormente resulta pertinente recuperar la voz de un/a entrevistado/a, quien establecía:

Una ley, la de educación sexual que se sancionó en el 2006, en la provincia recién el año pasado se adhirió y este año se reglamentó por el Ministerio de Educación por una resolución del Ministerio, que eso también no es habitual porque las reglamentaciones surgen de un Decreto del Ejecutivo.

El/la entrevistado/a hace alusión a que si bien la Ley 26.150 fue sancionada en el año 2006, recién nuestra provincia adhirió en el año 2018, lo que genera el interrogante de ¿por qué la provincia tardó 12 años en adherirse a la ley?, además, que sea reglamentada por el Ministerio de Educación y no por un decreto del Poder Ejecutivo, aquí podemos observar la necesidad de estos apoyos, argumentos, y antecedentes, que den existencia y estrategias de abordaje, según lo referido por los/las autores/as

La conexión entre el Estado y la Sociedad Civil, tiene en nuestro tema un fuerte protagonismo para alcanzar el "consenso social”, en términos de Rosemberg (Citado en Montaña, 2013, p.5): "no es solo un acuerdo cameral sino un desafío dialéctico, que va más allá, de la legítima preocupación acerca de accesibilidad al derecho, sino en darle identidad al sujeto”. La autora Montaña (2013) refiere: 
Si bien el marco constituyente que representa la ley 26.150, está social y políticamente legitimado en materia de ciudadanía de la infancia y ciudadanía juvenil, las resistencias a aplicar la ley siguen vigentes, numerosos son los obstáculos que se presentan a diario para derribar cánones conservadores y confesionales, que dificultan el proceso de apropiación de la génesis de ESI (p.5).

Teniendo en cuenta lo planteado en relación a la conexión entre el Estado y la Sociedad Civil, hacemos alusión a lo expuesto por un/a entrevistado/a: Cuesta interpretar que los derechos humanos que fueron reconocidos en la constitución del 94, y los tratados firmados por Argentina con otros países de rango internacional y constitucional (...), si bien el Estado tiene que garantizar la ESI, tenemos que estar todos capacitados y preparados.

En sumatoria, podemos añadir el siguiente relato de otro/a entrevistado/a:

Los responsables de educar a la gente somos nosotros, los profesionales. (...), debería haber capacitación más amplia, a todos los sectores, ya sea, educación, salud, desarrollo social y humano, también (...), en el contexto mucho más amplio, que algo más específico como la ESI en sí.

En concordancia, traemos a colación, que en muchos ámbitos organizacionales y en diferentes espacios sociales, se puede estar haciendo un análisis superficial de la Ley de ESI, en forma inconexa y descontextualizada de otras tantas leyes que le dieron génesis y fundamentación. Entre ellas podemos mencionar la Ley de Educación Nacional N²6.206/06, que por ejemplo establece en su artículo cuarto, la responsabilidad de proveer una educación integral, que garantice la igualdad, gratuidad y equidad en el ejercicio de este derecho, con la participación de las organizaciones sociales y las familias; o su concatenación con la Ley 25.673/02 del Programa Nacional de Salud Sexual y Procreación Responsable la cual menciona en su artículo $2^{\circ}$ (entre otros objetivos) el inciso por medio del cual se debe garantizar a toda la población el acceso a la información, orientación, métodos y prestaciones de servicios referidos a la salud sexual y procreación responsable. Estas "descontextualizaciones" legales a las que hacemos mención, podrían ser objeto de estudio contemplados en investigaciones futuras.

Retomando la relación entre Estado y Ciudadanía, el enfoque desde los Derechos Humanos, pone en escena el intercambio en el ejercicio de los derechos fundamentales, incluyendo el derecho a vivir una sexualidad plena, valorada desde la horizontalidad, que las instituciones del Estado y quienes asumen su representación tendrían que garantizar. 
Para hablar de ESI en el marco de los Derechos Humanos, indefectiblemente hay que mencionar los Derechos Sexuales y Reproductivos, y no reproductivos, reconocidos muy recientemente en este enfoque, con legislación propia de pocos años en nuestro país.

Desde la posibilidad que nos ofrece la ESI, vamos a ratificar que niños, niñas y adolescentes son personas con derechos, personas capaces de ejercer sus propios derechos, y que es, desde la educación formal, donde se fortalecen las infancias y las juventudes, en esta capacidad de conocer y comprender el ejercicio de la ciudadanía; que considere prioritaria la formación desde temprana edad, superando los modelos tradicionales; que permita superar prejuicios y afianzar el respeto a las diferencias y al goce de los propios derechos.

A partir de la posibilidad que nos ofrece la ESI, nos parece importante señalar el siguiente relato de un/a entrevistado/a:

Tendríamos que tener formación desde los ámbitos, no solamente desde los profesorados, también (...), las carreras de grado (...), hay muy pocas facultades que tienen alguna cuestión de perspectiva de género, derechos humanos, tendría que ser materias que estén desde primer año hasta el último, que sean progresivas y que sean transversales (...), dentro de la ley de educación el ámbito principal o donde todos podemos acceder (...), es la educación formal (...), la educación primaria y secundaria como obligatorias (...), ahí es donde más masividad puede llegar a tener, pero en todos los ámbitos que nos movemos también.

En principio, el/la mismo/a hace mención de las falencias presentadas en ámbitos de formación académica en carreras de grado. Consideramos que en la actualidad, el hecho de que los "Derechos Humanos" sean fundamento y objeto de estudio de las Ciencias Sociales, hace que no se les brinde la importancia necesaria en otros ámbitos académicos, como por ejemplo, desde la formación universitaria de las Ciencias Exactas. A su vez podría deducirse que, dificultará el hecho de brindar conocimientos de ESI desde la "transversalidad" que menciona la ley.

Además hace referencia a la "masividad" adjudicada a los espacios educativos obligatorios, nos interrogamos acerca de si la ESI estaría garantizada (más aún su accesibilidad) a niños/as y adolescentes que no se encuentran nucleados/as o comprendidos/as en dichos espacios, y que por razones de diversa índole se encuentran "excluidos/as" del sistema escolar. En sumatoria, agregamos el siguiente relato: "Entonces tiene que tener un acompañamiento gradual, serio (...), no puede estar resignada la educación sexual a un método anticonceptivo". 
En contraste a lo expuesto, se observa una analogía en el último testimonio, acerca "de resignar la educación sexual a un método anticonceptivo", una íntima vinculación al reduccionismo, aún vigente, y relacionado al modelo de riesgo. Montaña (2013), citando los Lineamientos Curriculares para la ESI, comenta que:

El discurso institucional estatal, a cargo de instalar esta política pública plantea que la Ley $\mathrm{N}^{\circ} 26.150$ recoge los principios constitucionales de igualdad y de no discriminación, y en su contenido teórico propone una cultura democrática que promueve la participación y el acceso a procesos de información, comunicación y educación con alcance amplio y universal (p.3).

La autora Montaña (2013) agrega además que, "la ley no dista este derecho de la horizontalidad social y educativa, para explicitar una vez más que la educación pública, laica y gratuita debería garantizar la igualdad de oportunidades” (p.3).

Teniendo en cuenta lo anterior, y lo planteado sobre el derecho a la horizontalidad socioeducativa, exponemos que es "necesaria, urgente y a su vez universal" la accesibilidad a la ESI.

El siguiente relato alude en forma directa al hecho de que la ESI, inscrita en el contexto de la Educación como Institución, debe ser de alcance universal, en plena concordancia con lo detallado por el autor. En otros comentarios un/a entrevistado/a nos comenta en relación a los espacios donde brindar ESI: “EEn qué ambientes? En todos lados, se puede en esa sala de espera, con cada paciente, con cada alumno, con cada compañero de la facultad (...), todos los ambientes, son pasibles de ser espacios de educación (...), de buena educación”.

En la descripción brindada por el/la entrevistado/a, se hace alusión a la implementación de la ESI desde ámbitos, espacios e instituciones que, en forma directa deben propugnar a la accesibilidad y horizontalidad, para la protección de la libertad ciudadana, garantizando el conocimiento y la Ley 26150/06 como derecho. Por otro lado se nos refiere que:

El trabajador social le da ese toque social, participativo que le da una diferente mirada (...), educación tiene que dar educación sexual integral y se cierran (...), el ministro de salud, de educación, de desarrollo social deberían ver qué hacemos, cómo la implementamos, (...), y si te vas a lo más micro, el referente de un barrio con él (...), de otro barrio (...), unión vecinal (...), para ver que hacemos en nuestros barrios (...), es un trabajo en red de intervención interinstitucional.

El/la entrevistado/a cita en sus palabras, lo que para él/ella implica (desempeñando sus actividades desde la docencia y la enfermería) el rol de un/a 
trabajador/a social en relación a la ESI, destacando la vinculación del/la mismo/a con la participación; también hace alusión de cuál debería ser "el ideal" de trabajo en cuanto a llevar la transversalidad de la ley, desde un espacio micro a macro-social. Por otro lado, también hace referencia a un trabajo en red, el cual ha sido bastante desarrollado y utilizado por el Trabajo Social en su trayectoria de conformación, trayendo a colación la inter-institucionalidad. Desde nuestra postura, deberíamos fijarnos como meta, el lograr un trabajo mancomunado desde la transdisciplinariedad ${ }^{8}, \mathrm{y}$ de ese modo garantizar esta base democrática e igualitaria que menciona el autor.

La importancia de la incorporación con fuerza legal de la ESI dentro del sistema escolar, radica en el reconocimiento de la sexualidad como derecho, y de los/as niños/as y adolescentes como ciudadanos/as. Este reconocimiento se basa y amplía, el espectro de los derechos sexuales, reproductivos y no reproductivos. El derecho a la sexualidad contempla dos dimensiones: la individual y la colectiva. La primera hace referencia al reconocimiento al derecho de la autonomía personal y a la privacidad. La segunda hace referencia al reconocimiento del Estado como garante último de los efectos sociales, económicos, culturales y sanitarios del ejercicio de la sexualidad de la población.

Dicho en otros léxicos, esta ley se encuadra en la frontera misma, entre lo público y lo privado, exigiendo respuestas a cuestionamientos sobre los principios significativos que pueden garantizar una educación democrática que contemple la libertad de las personas a decidir sobre su vida sexual, perteneciente a la esfera más íntima de las mismas, y el interés público/social por las consecuencias sociales, políticas y culturales de la sexualidad.

De acuerdo a lo planteado anteriormente sobre la introducción de la ESI, en los confines entre lo público y lo privado, se hace alusión al siguiente relato:

No debería ser en un solo ámbito (...), debería ser un tema que se trate en muchos lugares (...), tener un lugar donde recurrir a buscar ayuda, apoyo (...), que te abran la cabeza un poco (...), vas a encontrar de todo, padres que están muy accesibles (...), y (...), gente que es muy cerrada (...), entonces debería ser tratado en varios lugares.

En el comentario efectuado precedentemente, se hace hincapié en esta vinculación entre familia-estado ("un lugar donde recurrir") en correlación con los límites establecidos entre el ámbito público y privado, intersección profundamente ligada con el campo de intervención del Trabajo Social.

\footnotetext{
${ }^{8}$ La transdisciplina representa la aspiración a un conocimiento lo más completo posible, que sea capaz de dialogar con la diversidad de los saberes humanos. (Morín, 2019)
} 
La ESI garantiza el derecho de niños/as y adolescentes a la libertad de expresión y a ser oídos/as, y ese derecho incluye buscar, recibir y propagar informaciones de todo tipo. Es por este motivo que es pertinente mencionar en discursos de la autora Morgade (2010) lo siguiente:

El acceso a la educación sexual constituye la puerta de entrada para la articulación de la escuela en situaciones de vulneración de derechos, como violencia, abuso, maltrato contra los niños, que orientan hacia la búsqueda de medidas de protección y reparación necesarias (p.44).

En lo que se refiere a lo expuesto precedentemente, en relación a la ESI como puerta de entrada para articular con las escuelas y fortalecer los derechos de niños/as y adolescentes, se expresan los siguientes relatos:

Es muy importante (...), la comunicación (...) el rol del trabajador social y el psicólogo, profesionales que se dedican al estudio de la persona, de la realidad social (...), si la ESI no está implementado desde una materia curricular, debería estar manejado desde un gabinete

Además, uno/a de los entrevistados/as, hace la siguiente alusión:

Ustedes [refiriéndose a los/as profesionales de trabajo social], tienen la posibilidad (...), desde el contacto directo empezar a trabajar con la educación sexual, no hace falta que estén en un gabinete de una escuela, que estén dando clases en un instituto de formación, entonces lo veo mucho más permeable y mucho más abierta.

Y en sumatoria sugiere que: "Se pueden armar equipos de trabajo que vayan institución por institución. Esa es otra estrategia”.

Se pueden observar diversas miradas, en las cuales se evidencian las profesiones de los/las entrevistados/as, dando lugar a diferentes modos de garantizar los derechos de niños/as y adolescentes, a través de la distribución de información pertinente desde distintos espacios de intervención del Trabajo Social; (por ejemplo, gabinetes, equipos interdisciplinarios, entre otros).

A través del artículo d4e la Ley Federal del Trabajo Social, N²7.072/14, las prácticas propias del ejercicio profesional promueven el cambio, el desarrollo social y el empoderamiento de las personas, involucrando a estas y sus estructuras para hacer frente a desafíos de la vida y aumentar el bienestar.

Es por ello, que desde nuestra posición consideramos que desde el trabajo social, se pueden realizar una amplitud de acciones, a ser desarrolladas no solo desde los gabinetes y equipos interdisciplinarios (como plantean los entrevistados/as), 
sino también desde la transdisciplinariedad, combinando un conjunto de saberes diversos, para poder complementarse. A su vez, el desempeño de acciones profesionales de problemáticas sociales que residen, inciden y permanecen sin cuestionamientos en la realidad (partiendo desde la relación teoría-práctica), son asuntos significativos y urgentes, donde la profesión del Trabajo Social puede y debe, desde sus principios éticos, intervenir con sus metodologías y saberes construidos.

\section{Conclusiones}

A lo largo del presente artículo nos propusimos visibilizar los posibles motivos por los cuales se debate la implementación de la ley de Educación Sexual Integral en la provincia de San Juan. Para ello, en primera instancia, se identificaron las concepciones al respecto de la sexualidad que presentaban las personas entrevistadas en relación a sus imaginarios sociales. En segundo lugar, buscamos visibilizar la posible existencia de prejuicios que podrían influir en su ejecución. A partir de este recorrido, es preciso resaltar que la investigación desarrollada contó con ciertos ejes centrales que transversalizan ambos objetivos. Dicha consideración, inquiere a lo largo de la investigación descrita, de problematizar de una forma crítica aquellas dimensiones individuales y sociales, que inciden en la construcción cultural de una sexualidad estrictamente limitada y sesgada por diversos factores.

Dentro de los mandatos socio-culturales identificados que influyen en el ideario provincial, podemos destacar los siguientes: la heteronormatividad, la existencia de roles preestablecidos (entre ellos, la visión de la mujer como madre), la normatividad, moralidad, normalidad, el conservadurismo, los contextos o entornos de origen de las personas, los silenciamientos y prohibiciones, pensamientos categóricos, estigmatización de la diversidad, temores, tabúes y negaciones.

A su vez, llegamos a la conclusión que coexisten distintos modelos teóricos que inciden en el abordaje de la educación sexual, entre ellos los más representativos, el modelo médico-biologisista, y el modelo de riesgo. Estos generan requisitos y limitaciones en relación a los profesionales considerados aptos para brindar conocimientos acerca de la educación sexual, y a partir de ellos el diseño de distintas estrategias y herramientas de intervención que en ocasiones generan ciertos reduccionismos.

Otro aspecto en el que hacemos hincapié, es la confusión que generan los conceptos de sexualidad y género, por lo que, aclarando los mismos, inferimos que se promovería una interpretación real de la ley.

También consideramos importante, tener en cuenta las políticas públicas que se promueven o ponen en marcha desde el modelo de Estado vigente, ya que 
dependiendo de su adhesión, puede generar un impacto en la población garantizando o no, sus derechos y garantías.

Por lo que nos preguntamos, ¿desde dónde se ejerce el silenciamiento y las prohibiciones? Desde un nivel macro, ¿son los entes decisorios quienes favorecen el respeto por los idearios provinciales?, desde un nivel micro, ¿es la sociedad sanjuanina en general la que busca resguardar sus mandatos socio-culturales? ¿O ambos?, interrogantes que podrían tenerse en cuenta para futuras reflexiones.

En referencia a identificar el rol del/la Trabajador/a Social en los diversos escenarios de actuación profesional, con respecto a la implementación de la Ley de Educación Sexual Integral, consideramos necesarios realizar una lectura exhaustiva y un análisis en profundidad de las leyes que la originan, para de esta forma, lograr una interpretación contextualizada de la misma, contribuyendo a la construcción de políticas públicas y a su ejecución, tomando como sustento las herramientas que dan base a profesionales críticos que acompañan los procesos históricos de las comunidades, promoviendo las transformaciones que demanda la sociedad, siendo las políticas las que constituyen una manera específica de vínculos sociales entre instituciones, que favorecen $\mathrm{u}$ obstaculizan la accesibilidad a bienes y servicios.

Habría que decir también, que existe una fuerte impronta de los modelos médicos hegemónicos en la conformación histórica del trabajo social, reforzando que no se legitime el rol, produciendo consecuentemente, la cesión de espacios a otras profesiones consideradas "más aptas" para la implementación de la ESI (por ejemplo, médicos/as, docentes, psicólogos/as, etc.).

Consideramos de gran importancia hacer hincapié en el término de transdisciplinariedad, y en el enfoque orientado a problemas compartidos (como lo es la ESI), así como también en la contribución activa no solo desde el ámbito académico, sino desde una conjunción de diferentes miradas y espacios, interseccionalidad en la que el trabajador social, desde una mediación activa, se encarga de aplicar su especificidad en el área más amplia y compleja de las decisiones socio-políticas, orientando una intervención con base en derechos, o hacia una intervención sustentada en el control social.

A partir de todo lo descrito precedentemente, se observa que en los resultados obtenidos mediante las entrevistas, pueden corroborarse la existencia de imaginarios sociales y prejuicios que interfieren en la implementación de la ESI. Es por ello que consideramos fundamental, legitimar el rol del/la trabajador/a social para favorecer la identificación y apropiación de los espacios de intervención en la implementación de la Ley 26.150 en nuestra provincia. 


\section{Referencias bibliográficas}

Adorno, T. W.; Frenkel-Brunswik, E; Levinson, D. J.; Nevitt Sanford, R. (2006) La Personalidad Autoritaria. EMPIRIA. Revista de Metodología de las Ciencias Sociales, núm. 12, julio-diciembre, pp. 155-200

Bonaccorsi, N. y Reybet, C. (2008). Derechos sexuales y reproductivos: un debate público instalado por mujeres.

Revista LiminaR. Estudios sociales $y$ humanísticos. Volumen VI, No2 (pp.52-64). ISSN 1665-8027. Recuperada de http://www.scielo.org.mx/pdf/liminar/v6n2/v6n2a4.pdf

Burin, M (1998). Género y Familia. Editorial: PAIDOS

Casas M., M. de la L. (2008). Prejuicios, estereotipos y discriminación. Revista Acta Bioethica. Volumen 14, No2 (pp. 148-156). Recuperado de https://scielo.conicyt.cl/scielo.php?script=sci_arttext\&pid=S1726$569 X 2008000200004$

Del Olmo, M. (2005). Prejuicios y estereotipos: un replanteamiento de su uso y utilidad cómo mecanismos sociales. Revista de Educación de la Universidad de Huelva, $N^{o} 7$ (pp 13-23). Issn: 1575-0345. Recuperado de http://rabida.uhu.es/dspace/bitstream/handle/10272/1957/b15162084.pdf ?sequence $=1$

Duranti, R. (2011). Diversidad sexual: Conceptos para pensar y trabajar en salud.

Dirección de Sida y ETS. Ministerio de la salud de la Nación.

Korinfeld, D. (2005). Capítulo 3, Sexualidades. En Cuadernillo del Programa Nacional de Salud Sexual y Procreación Responsable. Una mirada sociocultural Programa Nacional de Salud Sexual y Procreación Responsable. Jóvenes y Sexualidad (pp. 47-75). Recuperado de http://www.uepc.org.ar/conectate/wp-content/uploads/2014/04/Jovenesy-sexualidad-Ministerio-de-salud.pdf

Morgade, G. (2010). Un derecho adquirido, Educación Sexual Integral. Voces en el Fénix. Volumen No 3 (pp. 42-45). Recuperado de www.vocesenelfénix.com

Morín, E. (2019). Qué es la Transdisciplinariedad. Recuperado en https://edgarmorinmultiversidad.org/index.php/que-estransdisciplinariedad.html

Niremberg, O. (2013). Capítulo I Intervenciones Sociales. En O. Niremberg, (Ed). Formulación y evaluación de intervenciones sociales. Políticas-PlanesProgramas-Proyectos (pp. 31). Noveduc libros Ediciones.

OMS, Organización Mundial de la Salud (2018). La salud sexual y su relación con la salud reproductiva: un enfoque operativo. Documento de informe. ISBN 978 
https://apps.who.int/iris/bitstream/handle/10665/274656/978924351288

4-spa.pdf

Página Oficial del Gobierno de la República Argentina (2014). Ley Federal de Trabajo Social, No 27072/14. Recuperada de https://www.argentina.gob.ar/normativa/nacional/ley-27072

Página Oficial del Gobierno de la República Argentina (2004). Ley Nacional de Educación, No 26206/06. Recuperada de https://www.argentina.gob.ar/educacion/valideztitulos/glosario/ley26206

Página Oficial del Gobierno de la República Argentina (2002). Ley de creación del Programa Nacional De Salud Sexual Y Procreación Responsable, No Ley $25673 / 02$.

Recuperada de https://www.argentina.gob.ar/normativa/nacional/ley-25673-79831

Página Oficial del Ministerio de Justicia y Derechos Humanos. Presidencia de la Nación. Programa Nacional de Educación Sexual Integral. Ley de Educación Sexual Integral, No 26150/06. Recuperada de http://servicios.infoleg.gob.ar/infolegInternet/anexos/120000124999/121222/norma.htm

Sampieri Hernández, R. (5a Ed.) (2010). Metodología de la Investigación. Editorial McGraw.Hill. Recuperado de https://metodologiaecs.wordpress.com/2013/02/20/libro-metodologiade-la-investigacion-5ta-ed-sampieri/comment-page-2/ , pp 406-487

Villar, M., Wickler, M. y Zapata, A. (2016). Mitos y resistencias que obstaculizan la implementación de la Educación Sexual Integral. Algunas reflexiones en torno a la investigación realizada en tres instituciones de Santa Fe. En VI Coloquio interdisciplinario internacional de "Educación, sexualidades y relaciones de género"; 4to Congreso de género y sociedad, organizado por la Universidad Nacional de Córdoba y llevado a cabo en la Provincia de Córdoba (Argentina). Recuperado de http://conferencias.unc.edu.ar/index.php/gyc/4gys/paper/viewFile/4242/ 1522

Ramos G. A. (2009). Discursos que construyen sexualidades en escuelas medias de la ciudad de Buenos Aires. En A. Villa (Comp.), Sexualidad, relaciones de género y de generación; Perspectivas histórico-culturales en educación (pp. 139-169). Editorial Noveduc. Colección Ensayos y Experiencias. ISBN 978987-538-251-O.

UNESCO, Organización de las Naciones Unidas para la Educación, la Ciencia y la Cultura (2014). Educación Integral de la Sexualidad: Conceptos, Enfoques y 
Competencias. Biblioteca Digital Unes.doc, documento de programa recuperado de https://unesdoc.unesco.org/ark:/48223/pf0000232800

Villa, A. (2009). Sexualidad, relaciones de género y de generación; Perspectivas histórico-culturales en educación. Editorial Noveduc. Colección Ensayos y Experiencias. ISBN 978-987-538-251-O.

Villa, A. (2007). Cuerpo, sexualidad y socialización; Intervenciones e investigaciones en salud y educación. Editorial Noveduc. Colección Ensayos y Experiencias. ISBN 978-987-538-251-O. 